\title{
Spatial clustering and risk factors of infant mortality: district-level assessment of high- focus states in India
}

\author{
Ashish Kumar Gupta ${ }^{*}$, Laishram Ladusingh ${ }^{2}$ and Kakoli Borkotoky ${ }^{1}$
}

\author{
* Correspondence: \\ ashishatbhu@gmail.com \\ ${ }^{1}$ International Institute for \\ Population Sciences (IIPS), Mumbai, \\ India \\ Full list of author information is \\ available at the end of the article
}

\begin{abstract}
The study analyzes the spatial clustering and risk factors of infant mortality across high-focus states of India, using the Annual Health Survey (2010-2011), Census of India (2011), and District Level Household and Facility Survey-3 (2007-2008). Research has found substantial spatial autocorrelation across the districts and identified the "hot spots" characterized by higher infant mortality rate (IMR) in the districts of the central region (Uttar Pradesh and Madhya Pradesh) of India. This study has considered several theoretical perspectives and implements a series of spatial regression models that allows accounting for household amenities and mother/child and health facility variables to determine the key risk factors of infant mortality. Our empirical analysis underscores the importance of the infrastructure of the health facility in improving the infant mortality scenario of the districts. The regression results show that the districts with a higher proportion of 24-h functioning primary healthcare centers have overall less infant mortality. In addition, the absence of drinking water from a treated source, unavailability of toilet facilities, and higher proportion of people in the bottom wealth quintile in the household were adversely associated with the IMR. In conclusion, reduction of infant mortality would be possible only if area-specific measures would be adopted on those clusters of districts where infant mortality is high irrespective of the state they belong to.
\end{abstract}

\section{Background}

Infant and child survival depend on a host of socioeconomic, environmental, and contextual factors. Determining the contribution of each of these factors provides useful feedback to the programs related to maternal and child health. The distribution of infant and child mortality and their determinants vary across genders, socioeconomic groups, and geographical regions. Mapping of the variation in infant mortality can help in improving programs in terms of the allocation of limited resources to those regions with high unmet needs of healthcare. It is also widely accepted that infant mortality is an indicator of both economic and social wellbeing and represents multiple social determinants of health (Rodwin and Neuberg, 2005).

Although infant mortality is declining worldwide, the pace of decline has been rather slow in India. A further concern is that it is uneven across regions and socioeconomic groups. Reduction in infant mortality is the major focus of India's maternal and child 
health programs from their inception (James 2014). However, given the current rate of decline and assuming a linear trend, India's infant mortality rate (IMR) would be about 42 in 2015. At this pace, the MDG 4 target of 28 would only be achieved in 2023-2024 (Reddy 2012). The unsatisfactory pace of decline of infant mortality is largely attributed to regional inequality in the improvement of IMRs. There is a cluster of states, namely Uttar Pradesh, Uttarakhand, Bihar, Jharkhand, Chhattisgarh, Odisha, Madhya Pradesh, Rajasthan, and Assam that has higher infant mortality than India's national average. More significantly, these states have $48.5 \%$ of India's population and thus shape national targets related to infant and child mortality.

According to SRS (Registrar General of India 2014), the four states of Madhya Pradesh (MP), Assam (AS), Uttar Pradesh (UP), and Odisha (OD) have IMRs above 50, the highest in the country. However, state-level infant mortality has masked the intradistrict clustering of infant mortality. An empirical examination of district-level infant mortality revealed that the numbers of districts having IMR above their respective state averages are 28 out of 45 in MP, 9 out of 23 in Assam, 34 out of 70 in UP, and 12 out of 30 in Odisha (RGI 2012).

The slow decline of infant mortality has been the concern of policy makers and researchers equally. The National Rural Health Mission (NRHM) by the Government of India in 2005 is regarded as the flagship public health program for improving infant and child health. Although significant progress has been achieved in this direction, the improvement is not uniform across regions/sub-groups of population in the high-focus states (Hussain 2011; Programme evaluation organization 2011). The high-focus states were designated as such by the Indian government because of their persistently high IMRs. In the context of intra-district variation in infant mortality, the main questions that emerge are as follows: Where are the "hot spots" of infant mortality in the highfocus states? Whether maternal- and child-level factors at the aggregated level are enough to explain regional disparity in IMR? Would district-level contextual factors be more appropriate for programmatic intervention? Could emphasis on health infrastructure in primary healthcare centers further improve infant survival? The objective of this paper is to address some of these questions by investigating the determinants of IMR in the high-focus states of India.

There is a sufficiently large body of documented research investigating the sociodemographic covariates of infant and child mortality. For decades, demographic research has pointed out that sociodemographic factors such as age of the mother, parity, birth interval, religion, place of residence, and standard of living/economic status have independent as well as combined effect on child survival (Stockel and Chaudhury 1972; Adlakha 1973; Hobcraft et al. 1984; Syamala 2004). Several studies have also emphasized the significant relationship between maternal characteristics such as education and age of the mother at the time of birth and infant and child mortality (Gubhaju 1985; Dasgupta 1990; Reichman and Pagnini 1997; Curtis et al. 1993; Sastry 1997). Some studies also discussed the ruralurban gap (or the urban advantage) in infant and child mortality (Dyson 1977; Cleland et al. 1992; Sastry 1997; Cai and Chongsuvivatwong 2006; Saikia et al. 2013). Besides, epidemiologist and medical geographers have long acknowledged geographic space and place as important determinants of health outcome disparities (Taylor 1975; Cutis and Rees 1998; Diez 2001; Krävdal 2004; Balk et al. 2004; Ladusingh and Singh 2006; Pradha and Arokiasamy 2006; Rodrigues et al. 2013). 
Earlier studies using geo-spatial analysis (Singh et al. 2011) found evidence of the importance of spatial risk factors in explaining differential IMRs in the region. Adjusting for biophysical and geographical factors, Kumar et al. (2012) showed the importance of health program initiatives in curtailing under-five mortality in the high-focus states. These analyses suggest that there is a strong geographic clustering in IMR and that a substantial portion of this patterning remains even after controlling for socioeconomic and demographic variables.

The present study contributes to the debate about intra-district differentials and risk factors of IMR by reintroducing geography in a number of ways. Firstly, the study used detailed information about the household amenities, sociogeographic, demographic, healthcare utilization, and health facility variables at the district level as risk factors of IMR using geo-spatial methods for the high-focus states. Secondly, health facility variables are included in the analysis to show the spatial association between the availability of health infrastructure and IMR in the high-focus states. Finally, the identification of risk factors which accounts for the unevenness in the pace of decline in IMR would provide feedback for the betterment of backward and underdeveloped high-focus states of India.

Our attempt is consistent with recent studies that focused on exploring macro-level determinants of child health (Gouda et al. 2015; Goli and Jaleel 2014; Bhattacharya and Cornilius 2011). We have tried to show that there is a high degree of spatial clustering in IMR. Detailed data were used to demonstrate that the geographical clustering persists even after controlling for all the known household, maternal- and child-level, healthcare, and health facility variables. Later, a series of spatial maps are developed to investigate whether the clustering of IMR in a given area is related to conditions in the neighboring areas. These maps show that being adjacent to areas with high IMR appears to be an important predictor of high mortality in that area. IMRs can increase (or decrease) in a given area because of conditions in that area or because the area is adjacent to another in which mortality is increasing (or decreasing) through a combination of both the factors.

\section{Data and methods \\ Data}

Data for analysis was drawn from 284 districts of the high-focus states. These states are Uttar Pradesh, Bihar, Rajasthan, Madhya Pradesh, Odisha, Jharkhand, Chhattisgarh, Uttarakhand, and Assam. The district-level data for all nine states were obtained from the Annual Health Survey (2010-2011), Census (2011), and District level household and facility survey (DLHS-3; 2007-2008).

Realizing the need for decentralized district-based health planning in India, the Office of the Registrar General, Government of India, implemented the annual health survey (AHS) in all 284 districts (as per the 2001 census) of the eight EAG states and Assam (for a 3-year period) during the 11th 5-year plan period (2007-2012). These nine states, which account for about $48.5 \%$ of India's total population, are designated as high-focus states in view of their poor maternal and child health outcome indicators and high fertility rates. For the first time in the country, the survey provides district-level estimates on a set of child mortality indicators, including infant mortality rate (IMR), under-five mortality rate (U5MR), neonatal mortality rate, and postnatal mortality rate in these high-focus states. AHS is the largest district-level survey in terms of sample size ever 
conducted in India and has been specially designed to generate estimates of IMR, neonatal and postnatal mortality rates, and U5MR at the district level. The sample size requirement is calculated for estimation of IMR within $1 \%$ relative standard error (RSE). The district-level estimate of IMR from AHS is statistically robust as it is based on a very large sample size as shown in the Appendix.

The present study used the district-level estimates on IMR provided by the AHS conducted during 2010-2011 in the nine high-focus states as outcome variables. ${ }^{1}$ Further, household economic condition and maternal and child healthcare variables given in the AHS were used as predictors of infant mortality. Census 2011 covered 640 districts including 7935 towns and 640,867 villages. District-level information on household amenities such as availability of drinking water from a treated source, percentage literate and working females in the households, and percentage of urban households with drainage and sanitation facilities in the high-focus states was modeled with IMR.

Besides, information related to health facilities has been extracted from the facility survey of DLHS-3 (2007-2008). DLHS is the only source of information on health facilities along with maternal and child health indicators at the district level.

\section{Description of the variables}

The unit of analysis is the districts. The outcome variable is the IMRs for selected districts. The choice of explanatory variables is guided by existing literature and an analytical framework proposed by Mosley and Chen (1984) to study the determinants of child survival in developing countries. The variables have been classified into the following categories: mother and child variables, those capturing household amenities, and indicators of utilization of healthcare services and health facilities (Table 1). Univariate, bivariate, and multivariate exploratory spatial data analyses (ESDA) such as Moran's I, univariate and bivariate local indicator of spatial correlation (LISA), and spatial regressions were used to assess the spatial clustering and risk factors of IMR in the high-focus states.

Access to toilet facilities, drinking water from a treated source, and availability of electricity were used as the proxy indicators of household amenities to examine their relationship with infant mortality. Variables such as birth interval, low birth weight, incidence of acute respiratory infection (ARI), and diarrhea are included in the analysis to control for the maternal/child confounders. In order to capture the effect of healthcare utilization on infant survival, variables such as mothers who received three or more ante natal care (ANC), percentage of women who had a safe delivery, and those who received postnatal care are included. In most of the literature available in the public domain, the component of health facility has not been investigated while analyzing the risk factors for IMR. In this study, health facility variables such as 24-h fully functioning primary health centers (PHCs), distance to the district hospital, population covered by a PHC, and 24-h operation theater (OT) have also been incorporated.

\section{Methods}

The methods used in this paper are described in the following sections. First, districtlevel maps of IMR were generated using Arc-GIS to determine the spatial patterns for the high-focus states of India. 
Table 1 Exposure variables used in spatial modeling the infant mortality in nine high-focus states in India, AHS (2010-2011) and DLHS-3 (2007-2008)

\begin{tabular}{|c|c|}
\hline Variables & Description/data source \\
\hline \multicolumn{2}{|l|}{ Dependent } \\
\hline IMR & $\begin{array}{l}\text { Total infant deaths aged below } 1 \text { year per } 1000 \text { live births (infant } \\
\text { deaths/total live births* 1000) (AHS 2010) }\end{array}$ \\
\hline \multicolumn{2}{|l|}{ Independent } \\
\hline ARI & $\begin{array}{l}\text { The information on children suffering from ARI in respect of all the } \\
\text { living children [last two outcomes of pregnancy(s) resulting in live } \\
\text { births during the reference period, i.e., 2007-2009] during } 15 \text { days } \\
\text { preceding the date the survey has been collected (AHS 2010) }\end{array}$ \\
\hline Diarrhea & $\begin{array}{l}\text { The information on children suffering from diarrhea in respect of } \\
\text { all the living children [last two outcomes of pregnancy(s) resulting in } \\
\text { live births during the reference period, i.e., 2007-2009] during } 15 \text { days } \\
\text { preceding the date the survey has been collected. (AHS 2010) }\end{array}$ \\
\hline Female work participation & $\begin{array}{l}\text { Total female workers irrespective of type of work/total female } \\
\text { population * } 100 \text { (Census 2011) }\end{array}$ \\
\hline Proportion of urban population & Total of urban population/total population * 100 (Census 2011) \\
\hline Bottom wealth quintile & $\begin{array}{l}\text { The wealth index is computed using household assets in AHS and } \\
\text { used in this study. Lowest quintile is considered in the analysis as } \\
\text { a proxy of low socioeconomic status (AHS 2010). }\end{array}$ \\
\hline Drainage facility & $\begin{array}{l}\text { Includes both open and closed drainage available in a household } \\
\text { (Census 2011) }\end{array}$ \\
\hline Drinking water from treated water & $\begin{array}{l}\text { Includes drinking water from a treated/untreated source, covered } \\
\text { well, and tube well/borehole/hand pump at the household level } \\
\text { (Census 2011) }\end{array}$ \\
\hline Improved toilet facilities & $\begin{array}{l}\text { Includes flush toilet, piped to a sewer system or a septic tank, and } \\
\text { a pit with slab/ventilated improved pit }\end{array}$ \\
\hline Average Household Size & Number of members in a household (AHS 2010) \\
\hline $\begin{array}{l}\text { Percentage of household with kachha } \\
\text { house/electricity }\end{array}$ & $\begin{array}{l}\text { Percentage of household with kachha house and electricity } \\
\text { (Census 2011) }\end{array}$ \\
\hline Drinking water from a treated source & $\begin{array}{l}\text { This is considered as the availability of drinking water from a } \\
\text { treated source in a household. (Census 2011) }\end{array}$ \\
\hline Percentage of SC/ST & (Percentage of SC/total population) * 100 (Census 2011) \\
\hline Percentage of literate women & Defined using percentage of literate women in district (Census 2011) \\
\hline Percentage of safe delivery & Based on proportion of women's reporting safe delivery (AHS, 2-11) \\
\hline $\begin{array}{l}\text { Percentage of women with more than } \\
3 \text { ANC }\end{array}$ & $\begin{array}{l}\text { Based on proportion of women's reporting more than } 3 \text { ANC } \\
\text { (DLHS-3) }\end{array}$ \\
\hline $\begin{array}{l}\text { Percentage of children who received } \\
\text { care within } 24 \mathrm{~h} \text { of birth (PNC) }\end{array}$ & $\begin{array}{l}\text { Based on proportion of women's receiving care within } 24 \mathrm{~h} \text { of } \\
\text { birth (DLHS-3) }\end{array}$ \\
\hline Percentage of women availed JSY & $\begin{array}{l}\text { Based on proportion of women's receiving care within } 24 \mathrm{~h} \text { of } \\
\text { birth (DLHS-3) }\end{array}$ \\
\hline $\begin{array}{l}\text { Proportion of PHC functional } 24 \mathrm{~h} \text { in } \\
\text { districts }\end{array}$ & $\begin{array}{l}\text { Calculated based on facility information whether PHC functional } \\
24 \text { h. (DLHS-3) }\end{array}$ \\
\hline Distance to district hospital & Based on facility information distance to district hospital (DLHS-3) \\
\hline $\begin{array}{l}\text { Percentage of } \mathrm{PHC} \text { with labor room } \\
\text { available in district }\end{array}$ & $\begin{array}{l}\text { Information obtained from facility survey percentage of PHC } \\
\text { having labor room (DLHS-3) }\end{array}$ \\
\hline Average population covered by PHC & Calculated based on facility information at PHC level (DLHS-3) \\
\hline
\end{tabular}

\section{Computation of spatial autocorrelation index}

The computation of spatial autocorrelation requires construction of a matrix known as spatial weight matrix $(W)$ to quantify the spatial proximity between each possible pair of observational units. The matrix can be constructed in different ways depending on the definition of the neighbor employed. The simplest way is to construct a binary 
connectivity matrix. An element $w_{i j}$ of a binary connectivity matrix $W$ equals unity if district $j$ adjoins district $i$ and equals zero in all the other cases. To observe the spatial clustering of infant mortality across districts, Moran's I Index is computed to measure the extent of the autocorrelation among the neighborhood sections of society. Spatial analysis software, GeoDa 1.6.0, is used to compute Moran's I statistic and to generate respective cluster maps (Anselin et al. 2006). The index used to observe spatial autocorrelation at the local level is Anselin's LISA, which can be seen as the local equivalent of Moran's I. For each location, LISA values allow for the computation of its similarity with its neighbors and also test its significance.

Five scenarios may emerge:

- Locations with high values, with similar neighbors (high-high). Such locations are also known as "hot spots."

- Location with low values, with similar neighbors (low-low). These are also known as "cold spots."

- Locations with high values, but with low-value neighbors (high-low). These locations are referred to as potential "spatial outliers."

- Locations with low values, but with high-value neighbors (low-high). These are referred to as potential "spatial outliers."

- Locations with no significant local autocorrelation.

\section{Bivariate LISA: spatial pattern in association between IMR and selected predictors}

The purpose of bivariate LISA is to analyze the association of certain characteristics of districts with their IMR level. In this section, an attempt has been made to explore the association between IMR levels of the area with those of the average neighboring value of another variable. For this purpose, the percentage of women who received more than three ANC and had a safe delivery, percentage of households in the bottom wealth quintile, and percentage of women who availed of Janani Suraksha Yojana (JSY) facilities are considered for the study of bivariate association.

\section{Spatial risk factors of IMR}

After confirming the presence of spatial autocorrelation in IMR across the high-focus districts, it is possible that such correlation in dependent variables may lead to correlation among the error terms rendering the ordinary least square (OLS) estimator inappropriate owing to violation of its underlying assumptions. Spatial regression technique is used to examine determinants of infant mortality.

\section{Spatial regression}

The "spatial effect" can be modeled in the following two ways:

Spatial lag model If the dependent variable, $Y$, is correlated with the weighted average of its value in its neighborhood and other locations, this relationship can be expressed as

$$
Y=\rho W Y+\beta X+\varepsilon
$$

Here, $\rho$ is the spatial lag parameter, $W$ is the spatial weight matrix, $X$ is the vector of explanatory variables, and $\beta$ is the corresponding coefficient vector. It is assumed here that the error term $\varepsilon$ is identically and independently distributed (iid) although one can 
correct for heteroscedasticity (Anselin et al. 2006). The OLS would, therefore, provide biased and inconsistent estimates of the model parameters due to simultaneity bias.

Spatial error model If the spatial dependence enters the model through the error term, $\varepsilon$, we can have the spatial error model represented as

$$
\begin{aligned}
& Y=\beta X+\varepsilon \\
& \varepsilon=\lambda W \epsilon+\mu
\end{aligned}
$$

Here, $\lambda$ is the spatial autoregressive parameter and the error $\mu$ is the iid. Thus, this is a special case of regression with a non-spherical error term and in which OLS, although unbiased, is inefficient. Therefore, here, the spatial regression takes into account proximity among geographical units through the weight matrix $W$. Both spatial error and spatial lag models are estimated by maximizing the corresponding likelihood functions discussed further by Anselin et al. (2006).

\section{Descriptive findings and model result}

The units of analysis are the districts. The results are entirely based on the aggregated district-level data. To display the spatial clustering of infant mortality, a series of maps were generated. Figure 1a is a quintile and Moran's I plot of IMR across 284 high-focused districts of India for the year 2010-2011. The red color in the quintile map indicates high IMR, and subsequently, the light shades display low levels of IMRs. Moran's I scatter plot of infant mortality shows the levels between each section and the average level of infant mortality of the contiguous section of the index sections. The quintile map demonstrates that areas in red are contiguous to each other, which suggests the clustering of a high level of infant mortality. It can also be seen that areas characterized by low IMR have a neighborhood with low IMR.

Thus, the four quadrants of the Moran scatter plot depict the section with high IMR (high-high) in a manner similar to the section characterized by low IMR surrounded by the section having low IMR (low-low) and the spatial outlier sections as low-high and high-low. Overall, Global Moran's spatial autocorrelation is 0.447 $(p<0.01,999$ permutations) implying moderate correlation but significant positive association with the levels of IMR in the high-focus districts. Therefore, there is a need to analyze spatial clustering at the local level to identify the areas with significant clustering of the values.

\section{LISA maps for IMR of high-focus districts}

For obtaining significant clustering of IMR values, we tried to generate the LISA cluster maps. The LISA cluster map (Fig. 1b) shows high-high clustering (red color), low-low clustering (green color), and the spatial outlier. From the cluster map, it can be seen that the red and green sections have significant neighborhood clustering and that the pattern cannot be analyzed by Global Moran's I autocorrelation index. We can also see that all hot-spot (high-high) districts are located in Uttar Pradesh and Madhya Pradesh (at a 5 \% level of significance), while the cold-spot (low-low) districts are located in Jharkhand and Uttarakhand. Before turning to spatial regression models, an attempt was made to show the spatial clustering of IMR and its association with the selected predictors. 


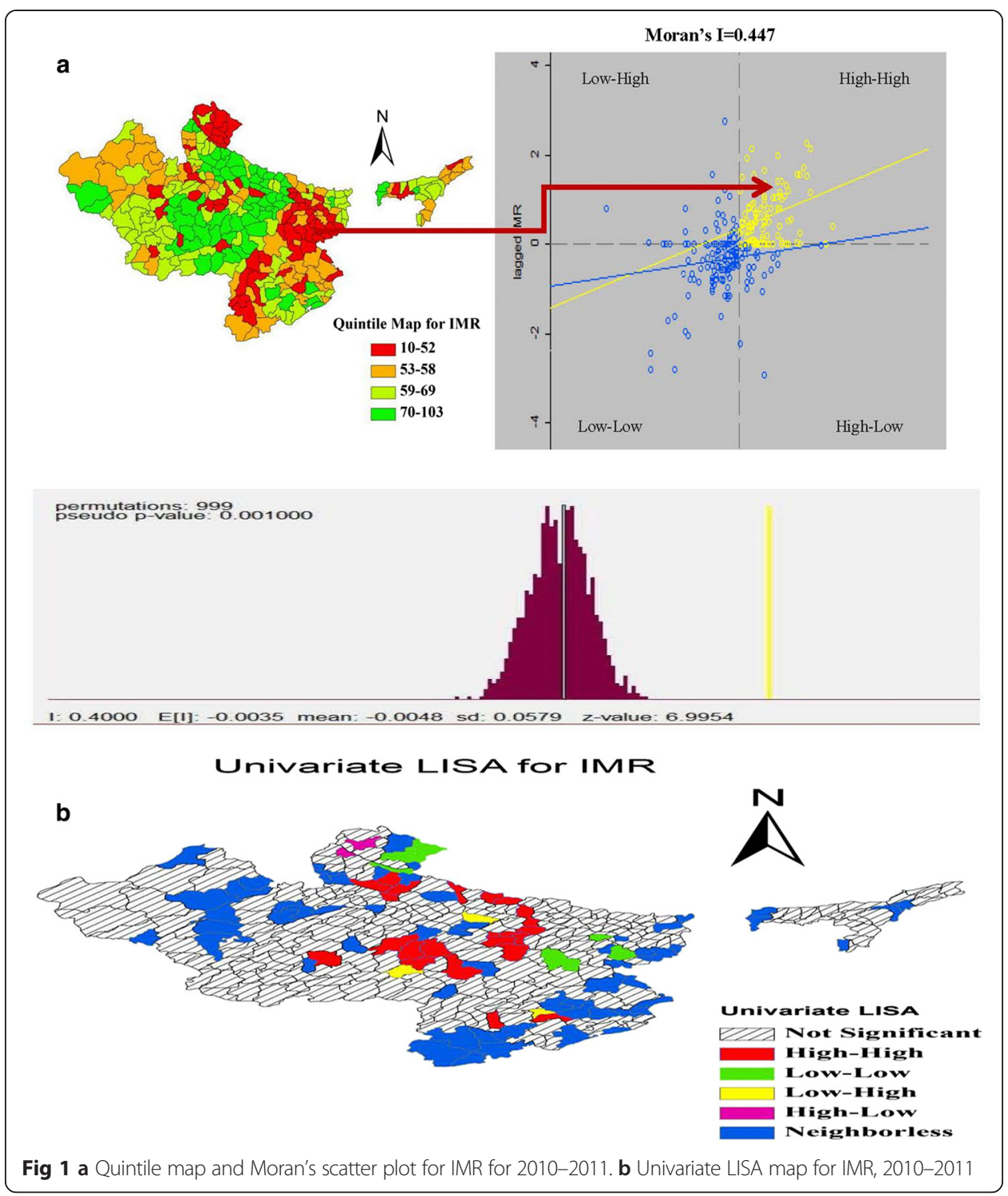

\section{Bivariate LISA statistic for IMR and selected predictors}

The bivariate LISA map provides visual support for the view that spatially dependent socioeconomic factors played a key a role in the spatial clustering of infant mortality (Fig. 2a-c). The result indicated 3 districts of Orissa and 18 districts from Madhya Pradesh were identified as hot spots where lack of utilization of ANC resulted in high IMR. The study identified 11 districts of Madhya Pradesh and 1 district of Rajasthan, where low percentage of safe delivery is associated with high infant death. Similarly, clustering was observed for two districts of Odisha and four districts each from Uttar Pradesh and Madhya Pradesh, where low utilization of JSY is associated with high infant mortality. Bivariate LISA also identified three districts in Rajasthan, four districts in Madhya Pradesh, and six districts in Uttar Pradesh as hot spots where higher percentages of households in the bottom wealth quintile resulted in high IMR. (Figure not presented for wealth quintile). 


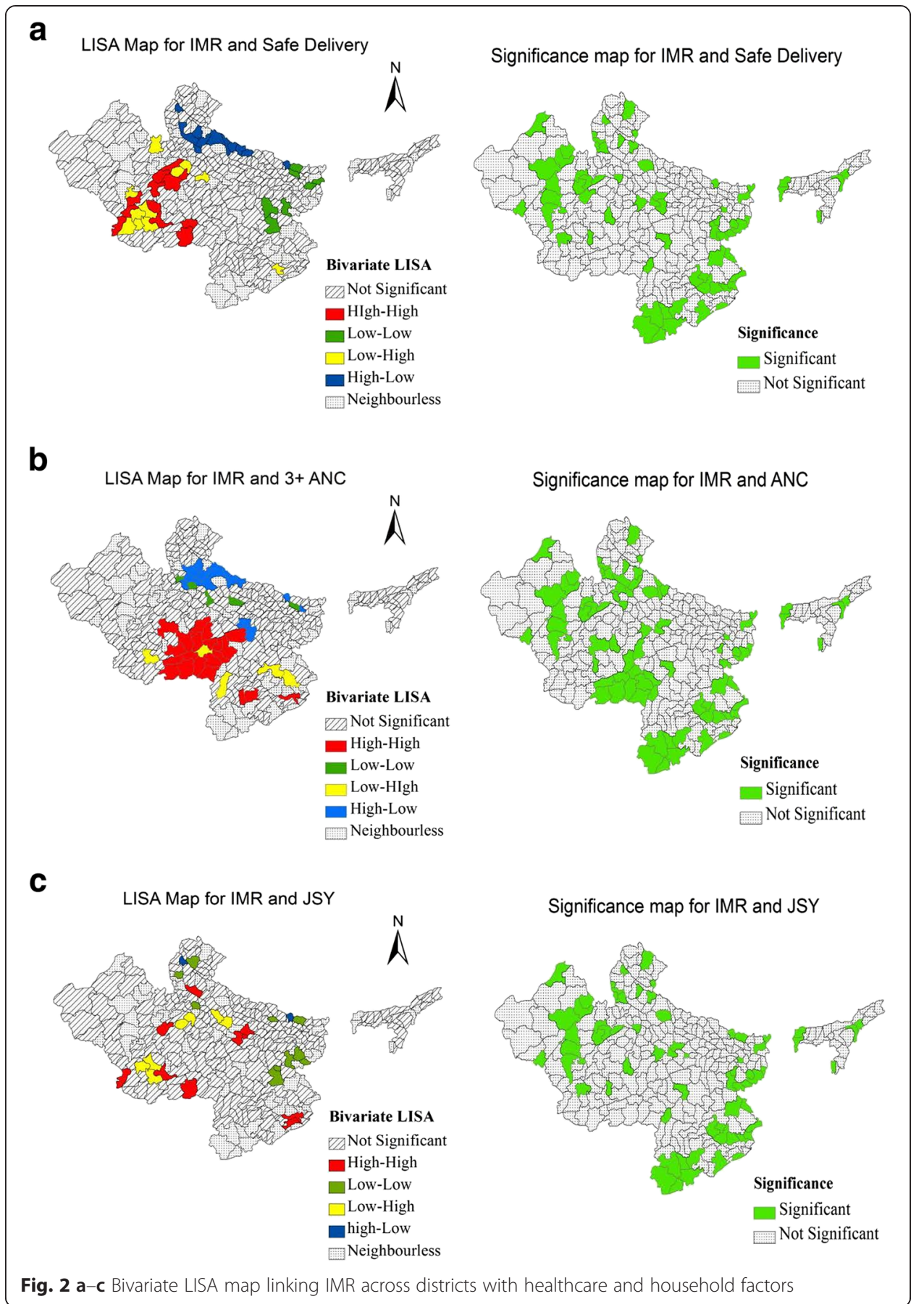

\section{Spatial regressions and diagnostics}

After confirming that there is significant autocorrelation in IMR across the 284 districts of high-focus states, the dependence structure in response to the variable indicates the possibility of unbiased coefficients of IMR according to the different risk factors. Hence, the spatial effect has been modeled in two ways as discussed earlier by estimating spatial lag as well as error model (Tables 2 and 3). The first panel shows the OLS estimates, and the second and third panels show estimates obtained using spatial error model and spatial lag model, respectively. We estimated five different models for each 
Table 2 Result of OLS model and spatial error model assessing determinants of IMR, High Focus States, 2010-2011

\begin{tabular}{|c|c|c|c|c|c|c|c|c|c|c|}
\hline \multirow[b]{2}{*}{ Characteristics } & \multicolumn{5}{|l|}{ OLS } & \multicolumn{5}{|l|}{ Error } \\
\hline & $\mathrm{HH}$ & Mother + child & Healthcare & Health facility & All & $\mathrm{HH}$ & Mother + child & Healthcare & Health facility & All \\
\hline$\%$ urban household & -0.033 & & & & -0.024 & -0.076 & & & & -0.041 \\
\hline$\%$ household in lowest quintile & $0.354^{* * *}$ & & & & $0.348^{* * *}$ & $0.338^{* * *}$ & & & & $0.361^{* * *}$ \\
\hline Treated water & $-0.194^{* *}$ & & & & $-0.286^{* * *}$ & $-0.236^{* * *}$ & & & & $-0.300^{* * *}$ \\
\hline Average household size & $4.286^{* * *}$ & & & & 2.496 & $5.382^{* * *}$ & & & & $2.964^{*}$ \\
\hline$\%$ household living in kachha house & -0.049 & & & & 0.004 & -0.070 & & & & -0.035 \\
\hline Access to improved toilet facilities & -0.001 & & & & $-0.168^{* * *}$ & 0.048 & & & & $-0.172^{* *}$ \\
\hline$\%$ household with access to electricity & 0.023 & & & & 0.004 & 0.025 & & & & 0.006 \\
\hline$\%$ household with no drainage facility & $0.067^{*}$ & & & & 0.041 & 0.035 & & & & 0.042 \\
\hline$\%$ of SC & $0.582^{* * *}$ & & & & $0.359^{* * *}$ & $0.524^{* * *}$ & & & & $0.376^{* * *}$ \\
\hline$\%$ of ST & -0.011 & & & & -0.028 & 0.023 & & & & -0.002 \\
\hline$\%$ women with literacy & & $-0.384^{* * *}$ & & & $-0.238^{*}$ & & $-0.265^{* * *}$ & & & -0.177 \\
\hline$\%$ working women & & -0.005 & & & 0.039 & & 0.033 & & & 0.070 \\
\hline$\%$ children with 3 years' birth interval & & $-0.182^{*}$ & & & -0.032 & & $-0.194^{*}$ & & & -0.004 \\
\hline$\%$ children with low birth weight & & 0.122 & & & 0.084 & & $0.135^{*}$ & & & 0.081 \\
\hline$\%$ children suffered from diarrhea & & $0.146^{* * *}$ & & & 0.006 & & $0.089^{*}$ & & & 0.005 \\
\hline$\%$ children who had ARI & & $0.318^{* * *}$ & & & $0.234^{*}$ & & $0.247^{* *}$ & & & $0.194^{* *}$ \\
\hline$\%$ children breastfed within $1 \mathrm{~h}$ & & -0.079 & & & -0.045 & & $-0.082^{*}$ & & & -0.045 \\
\hline$\%$ safe delivery & & & $-0.275^{* * *}$ & & $-0.211^{* * *}$ & & & $-0.196^{* * *}$ & & $-0.173^{* *}$ \\
\hline$\%$ women with $3+$ ANC & & & $-0.107^{* *}$ & & -0.055 & & & $-0.152^{* * *}$ & & -0.080 \\
\hline$\%$ children who received care within $24 \mathrm{~h}$ of birth & & & $-0.372^{* * *}$ & & $-0.444^{* * *}$ & & & $-0.357^{* * *}$ & & $-0.407^{* * *}$ \\
\hline
\end{tabular}


Table 2 Result of OLS model and spatial error model assessing determinants of IMR, High Focus States, $2010-2011$ (Continued)

\begin{tabular}{|c|c|c|c|c|}
\hline JSY & $0.264^{* * *}$ & $0.115^{* * *}$ & $0.176^{* * *}$ & $0.083^{* *}$ \\
\hline $24 \mathrm{~h} \mathrm{PHC}$ & -0.054 & -0.007 & $-0.075^{*}$ & -0.003 \\
\hline Distance to DH & -0.092 & 0.003 & 0.000 & -0.003 \\
\hline Labor room available & $-0.059^{*}$ & $-0.048^{*}$ & -0.012 & -0.038 \\
\hline Pop PHC & $0.000^{*}$ & $0.000^{*}$ & 0.039 & $0.000^{* *}$ \\
\hline
\end{tabular}


Table 3 Result of Spatial Lag model assessing determinants of IMR, High Focus States, 2010-2011

\begin{tabular}{|c|c|c|c|c|c|}
\hline \multirow[b]{2}{*}{ Characteristics } & \multicolumn{5}{|l|}{$\underline{\text { Lag }}$} \\
\hline & $\mathrm{HH}$ & Mother + child & Healthcare & Health facility & All \\
\hline$\%$ urban household & -0.069 & & & & -0.051 \\
\hline$\%$ household in lowest quintile & $0.337^{* * *}$ & & & & $0.346^{* * *}$ \\
\hline Treated water & $-0.180^{* *}$ & & & & $-0.283^{* * *}$ \\
\hline Average household size & $4.114^{* * *}$ & & & & 2.555 \\
\hline$\%$ household living in kachha house & -0.054 & & & & -0.002 \\
\hline Access to improved toilets facility & 0.019 & & & & $-0.180^{* *}$ \\
\hline$\%$ household with access to electricity & 0.027 & & & & 0.017 \\
\hline$\%$ household with no drainage facility & 0.069 & & & & 0.041 \\
\hline$\%$ of SC & $0.580^{* * *}$ & & & & $0.366^{* * *}$ \\
\hline$\%$ of ST & 0.002 & & & & -0.019 \\
\hline$\%$ women with effective literacy & & $-0.371^{* * *}$ & & & $-0.250^{* *}$ \\
\hline$\%$ working women & & -0.024 & & & 0.024 \\
\hline$\%$ children with 3 years' birth interval & & $0.196^{* *}$ & & & -0.009 \\
\hline$\%$ children with low birth weight & & $0.145^{*}$ & & & 0.098 \\
\hline$\%$ children suffered from diarrhea & & $0.139 * * *$ & & & 0.007 \\
\hline$\%$ children who had ARI & & $0.268^{* * *}$ & & & $0.201^{* *}$ \\
\hline$\%$ children breastfed within $1 \mathrm{~h}$ & & -0.054 & & & -0.023 \\
\hline$\%$ safe delivery & & & 0.128 & & $-0.207^{* * *}$ \\
\hline$\%$ women with $3+$ ANC & & & -0.115 & & -0.053 \\
\hline $\begin{array}{l}\% \text { children who received care } \\
\text { within } 24 \mathrm{~h} \text { of birth }\end{array}$ & & & $0.300^{* * *}$ & & $0.431^{* * *}$ \\
\hline JSY & & & -0.061 & & $0.097^{* *}$ \\
\hline $24 \mathrm{~h}$ functioning of $\mathrm{PHC}$ & & & & $-0.088^{*}$ & -0.066 \\
\hline Distance to $\mathrm{DH}$ & & & & $0.000^{*}$ & 0.001 \\
\hline Labor room available & & & & -0.048 & $-0.041^{*}$ \\
\hline Population covered by PHC & & & & $0.044^{*}$ & 0.000 \\
\hline
\end{tabular}

${ }^{* * *} p<0.01,{ }^{* *} p<0.05,{ }^{*} p<0.10$

of the spatial regression: model 1 has household characteristics and amenities, model 2 considered mother and child variables, model 3 has healthcare variables, model 4 has health facility variables in the analysis, and the last model incorporated all the variables. Considering significant autocorrelation in IMR, it can be inferred that the residuals of the OLS model are positively spatially correlated. Moreover, the study applied a diagnostic test for spatial error and lag models, for example, Lagrange's multiplier (LM) test for both the models. The study found that test statistics is significant. Coefficients of the terms capturing spatial effects, viz, $\lambda$ in spatial error model and $\rho$ in spatial lag model, are statistically significant. The positive value of $\lambda$ and $\rho$ indicates substantial spatial dependence in IMR across the neighboring districts (Table 4). It is also observed that the OLS model overestimates the coefficients; hence, the spatial error and lag models will be better for capturing the spatial effect in the model. Model 1 (household amenities), for both spatial error and lag models, indicates that the risk of infant death is lower for the districts with higher urban household (higher levels of urbanization), which is consistent with the findings of the earlier studies (Saikia et al. 2013) discussing urban-rural mortality divide. Similarly, we have found that districts with the higher 
Table 4 Spatial dependence and diagnostic analysis

\begin{tabular}{llll}
\hline Diagnostics test & OLS model & Spatial error model & Spatial lag model \\
\hline Adjusted R-squared & 0.428 & & \\
Lagrange multiplier (lag) & 10.071 & & \\
Lagrange multiplier (error) & 6.484 & & \\
$\Lambda$ & & 0.201 & \\
$\rho$ & & & 0.074 \\
AIC & 2194.711 & 2186.224 & 2186.521 \\
Breusch-Pagan test & 48.712 & 50.337 & 55.014 \\
\hline
\end{tabular}

proportion of households in the bottom wealth quintile were characterized by high IMR for both spatial regression models. Our analysis indicated that the district with a higher proportion of kachha houses and unavailability of toilet facilities has a higher IMR level, while the availability of treated water in the household was found to be negatively associated with the IMR. The subsequent model (model 2) integrated womenand child-level variables such as percentages of literate and working women, percentage of children with 3 years' birth interval, percentages of children with low birth weight, and percentage of children with ARI/diarrhea. The result suggests that female literacy have significant and negative association with IMR in both spatial models. It is also found that districts with a higher percentage of children suffered from diarrhea and those with a percentage of children breastfed within $1 \mathrm{~h}$ of birth have lower IMR. In model 3, the finding from both models indicated that the district with a higher proportion of literate women, percentage of women with 3+ ANC, and percentage of women who had safe delivery was negatively associated with IMR. In model 4, the IMR was modeled with health infrastructure variables. The result shows that variables such as the 24-h functioning of PHC and the availability of a labor room in the PHC in districts are also associated with the infant mortality to a certain extent. Model 5 included all the predictor variables, and the result shows that the association between maternal education, average household size, and IMR is significant. They have negative effect on infant mortality. Overall, we found that other household-level factors such as drinking water from treated source, access to toilet facility, electricity, proportion of SC/ST; maternal characteristics such as women with 3+ ANC and women who had safe delivery; and child-level characteristics such as percentage of children affected from diarrhea and percentage of children breastfed within the first hour of birth have statistically significant relationship with IMR. The results based on the facility model show that variables such as the 24-h functioning PHC and the availability of a labor room in the PHC in districts are associated with the infant mortality for both the spatial models.

\section{Discussions}

Despite the progress towards improving the pace of decline in infant mortality in these nine high-focus states during last four decades, India is sure to fall short of the child mortality-related Millennium Development Goal (Reddy 2012). Most of the research has highlighted the importance of maternal-, child-, and community-level variables as the factors that contribute to the slow decline of infant mortality. However, there are no studies that have used a comprehensive set of models based on potential household amenities, mother and child variables, and healthcare and health facility factors using exploratory spatial data analysis. This omission is related to the paucity of district-level 
information on socioeconomic and mortality indicators as well as the complexity involved in the spatial analysis. Spatial analyses are important for policy intervention at the district level as it explains intra-district variation more appropriately than by individual-, maternal-, or household-level factors. This paper assesses the significance of spatial clusters and risk factors in explaining the regional variation in IMR. However, there has been few attempts to analyze the association between spatial factors and child health indicators emphasizing change in contextual factors such as environmental covariates (Kumar et al. 2012) or spatial correlates (Singh et al. 2011). The novelty of the attempt is to render reasonable explanations of spatial clustering and risk factors of IMR by joining health and location data in the nine high-focus states.

The observed spatial pattern leads to computation of the strength of spatial clustering of infant mortality across the high-focus states of India. The significant positive Moran's I spatial correlation index of infant mortality suggests that similar traits (high/low mortality zone) are concentrated at some specific areal pockets not uniform over the whole high-focus states. The local indicator of spatial association (LISA) statistic identifies the district from the central and eastern regions (Orissa, Madhya Pradesh, Rajasthan, Bihar, and Uttar Pradesh) as the hot spot (having high infant death surrounded by high-value neighbors) and few districts of Jharkhand and Uttarakhand as the cold spot (low-low clustering). The bivariate LISA suggests that there are certain sections (districts) in the central and eastern regions of India that indicate the association of the selected predictor and IMR.

The analysis pointed out that the OLS model overestimated the coefficients of the model with lower $R$-square values. Hence, the spatial error and lag models were used for this purpose. The analysis suggests household amenities such as drinking water from treated sources and access to toilet facilities have significant association with infant mortality. In states such as Odisha, Uttar Pradesh, and Bihar, none of the districts make the mentioned amenities available to even half of the households. These are demographically important states since more than one third of infant deaths occur in these three states in India (RGI 2014). Many hypotheses have been proposed for the mechanism through which increased education could lead to reduction in infant and child mortality rates, through timely use of healthcare services, economic advantages, high autonomy, and improved status in family and society (Levine and Rowe 2009). This finding also supports the hypothesis that female education is one of the driving forces for reducing IMR. This finding is particularly imperative for these nine highfocus states in the wake of the fact that nearly three in five women in these states had no or below primary level education (Singh et al. 2013). According to the 2011 Census of India, 72 districts from the high-focus states had very low levels of female literacy (<50\%) (RGI 2011). More precisely, female literacy at the district level is crucial as a catalyst for the trickling down of good practices on child care including healthcare utilization. The significant inverse association between the aggregate female literacy rate and district IMR reiterates the importance of improving female literacy to pave the way for faster reduction in IMR. The significance of district-level female literacy in reducing infant mortality at the aggregate level is also a reflection of the sociocultural practices of women in Indian society, and this fact has been ignored by demographers, social statisticians, and population geographers (Ladusingh and Singh 2006). 
According to the Wilkinson income hypothesis (Wilkinson 1997), income inequality has deterrent effect on health outcome and it has been overlooked in analyzing regional variation in IMR in India. Wealth quintiles constructed on the basis of assets owned by households are a close approximation to income (Filmer and Pritchett 1999; Vyas and Kumaranayake 2006). Analyzing the effect of the proportion of households in the bottom wealth quintile on district IMR allows testing of Wilkinson's hypothesis. The finding that the higher the proportion of households in the bottom wealth quintile the higher is the IMR is a confirmation of this hypothesis and agrees with that of similar results (Shi 1999; Wilkinson 1992, 1999; Filmer and Pritchett 1999). The findings from spatial regression also confirm the positive association between percent of the household in the bottom wealth quintile and IMR. Intervention to increase access to livelihood can pave the way for reducing income inequality and reduce IMR. Factors related to pre- and postnatal care, e.g., ANC, safe delivery, PNC, and variables related to personal illness control such as recent episodes of ARI and diarrhea among children have statistically significant association with infant mortality, which is in concordance with other studies in India (Gokhale et al. 2002; Gouda et al. 2015). Interestingly, analysis reveals that labor force participation, birth weight, and birth interval were not associated with IMR in the spatial lag as well as error models.

This analysis further brings out that regional inequality of infant death within India is a major area of concern. The central region comprising Madhya Pradesh and Uttar Pradesh is the poorest in terms of infant deaths. One of the vital contributions of this study to existing literature is that the analysis has considered the health infrastructure variable as a crucial determinant of IMR. This study concluded that the increase in the population burden on PHCs has reduced the chances of survival; likewise, infrastructure in terms of manpower and newborn-care facility were significantly associated with survival of the infant. The results highlight that the well-functioning of PHCs especially the emergency obstetric care (labor room availability) matters in reducing infant deaths, particularly in the high-focus states.

\section{Conclusions}

Despite a consistent decline in infant mortality over the last decade or so, these rates remain high in India. Though demographic and epidemiological literature underscores the importance of geographic space in assessing clustering and risk factors of IMR, there has been no study examining the links between IMR and household amenities, $\mathrm{MCH}$ variable, and healthcare and infrastructure factors using exploratory spatial data analysis. Nationally representative household-level data with survey data on health facilities were linked to examine the spatial clusters and determinants of IMR. The findings help in theorizing the link between district IMR and its spatial determinants. The result of the analysis justifies the use of exploratory spatial data analysis for identifying population clusters with high-risk IMR. Reduction of infant mortality would be possible only if area-specific measures would be adopted. The focus should be on those clusters of districts where infant mortality is high irrespective of the states to which they belong. Strengthening the primary healthcare center in the context of 24-h availability of the labor room and the well-functioning of the PHC may help immensely in terms of averting newborn death. The use of spatial analysis is recommended as it can provide more accurate spatial patterns of infant mortality and thus allows public health authorities to closely monitor this indicator. In conclusion, achieving future infant and child mortality 
goals in India would be a realistic target, when concerted interventions are made to minimize barriers at the district level particularly in these nine high-focus states.

\section{Endnotes}

${ }^{1}$ http://www.censusindia.gov.in/vital_statistics/AHSBulletins/AHS_Factsheets_2011_ 12.html.

\section{Appendix}

Table 5 Sample size of annual health survey by states

\begin{tabular}{lllll}
\hline State & Districts & \multicolumn{2}{l}{ Sample units } & \\
\cline { 3 - 5 } & & $T$ & $R$ & $U$ \\
\hline Assam & 23 & 1784 & 1412 & 372 \\
Bihar & 37 & 2356 & 1981 & 375 \\
Jharkhand & 18 & 2109 & 1514 & 595 \\
Madhya Pradesh & 45 & 2557 & 1660 & 897 \\
Chhattisgarh & 16 & 1255 & 926 & 329 \\
Orissa & 30 & 2364 & 1798 & 566 \\
Rajasthan & 32 & 1841 & 1294 & 547 \\
Uttar Pradesh & 70 & 3927 & 2782 & 1145 \\
Uttarakhand & 13 & 2059 & 1474 & 585 \\
Total & 284 & 20,252 & 14,841 & 5411 \\
\hline
\end{tabular}

\section{Competing interests}

The authors declare that they have no competing interests.

Authors' contributions

AKG and LL contributed in conceptualizing the study. AKG and KB were responsible for the statistical analysis. All authors contributed to the interpretation of the data, and critically revised all versions of the manuscript and approved the final version.

Author details

${ }^{1}$ International Institute for Population Sciences (IIPS), Mumbai, India. ${ }^{2}$ Department of Mathematical Demography and Statistics, International Institute for Population Sciences (IIPS), Mumbai, India.

Received: 22 June 2015 Accepted: 8 March 2016

Published online: 14 July 2016

\section{References}

Adlakha, A. (1973). Fertility and infant mortality -an analysis of Turkish data. Demography India, 2(1), 56-76.

Anselin, L., Syabri, I., \& Kho, Y. (2006). GeoDa: an introduction to spatial data analysis. Geographical Analysis, 38(1), 5-22.

Balk, D., Pullum, T., Storeygard, A., Greenwell, F., \& Neuwman, M. (2004). A spatial analysis of child mortality in West Africa. Population, Space and Place, 10(3), 175-216.

Bhattacharya, P. C., \& Cornilius, C. (2011). Inequalities in child mortality in India. Asian Population Studies, 7(3), 243-261.

Cai, L., \& Chongsuvivatwong, V. (2006). Rural-urban differentials of premature mortality burden in south-west China. International Journal for Equity in Health, 5, 13-21.

Cleland, J., Bicego, J., \& Fegan, G. (1992). Socioeconomic inequalities in childhood mortality: the 1970s to the 1980s. Health Transition Review, 2(1), 1-18.

Curtis, S. L., Diamond I., \& McDonald J.W. (1993). Birth Interval and Family Effects on Post Neonatal Mortality in Brazil. Demography, 30(1), 33-43. doi:10.2307/20611861.

Cutis, S., \& Rees, I. J. (1998). Is there a place for geography in the analysis of health inequality? Sociology of Health and IIIness, 20(5), 645-672.

Dasgupta, M. (1990). Death clustering, mother's education and the determinants of child mortality in Rural Punjab, India. Population Studies, 44(3), 489-505.

Diez, R. A. V. (2001). Investigating neighborhood and area effect on health. American Journal of Public Health, 91(11), 1783-1789.

Dyson, T. (1977). Levels, trends and differentials of child mortality- A survey. World Health Statistics Report. 30(4), $25-48$. Filmer, D., \& Pritchett, L. (1999). The impact of public spending on health: does money matter? Social Science \& Medicine, 19(11), 1309-1323. 
Gokhale, M. K., Rao, S. S., \& Garole, V. R. (2002). Infant mortality in India: use of maternal and child health services in relation to literacy status. Journal of Health, Population and Nutrition, 20(2), 138-147.

Goli, S., \& Jaleel, A. C. (2014). What is the cause of the decline in maternal mortality in India? Evidence from time series and cross-sectional analyses. Journal of Biosocial Science, 46(3), 351-365.

Gouda, J., Gupta, A. K., \& Yadav, A. K. (2015). Association of child health and household amenities in high focus states in India: a district-level analysis. BMJ open, 5, e007589. doi.org/10.1136/bmjopen-2015-007589.

Gubhaju, B. B. (1985). Effects of birth order and maternal age on infant and child mortality in rural Nepal. Biology and Society, 2(1), 15-22.

Hobcraft, J. N., Mcdonald, J. W., \& Rutstein, S. O. (1984). Socio-economic factors in infant and child mortality: a crossnational comparison. Population Studies, 38(2), 193-223.

Hussain, Z. (2011). Health of the national rural health mission. Economic \& Political Weekly, 46(4), 53-60.

James, K. S. (2014). Recent shifts in infant mortality in India: an exploration. Economic and Political Weekly, 49(3), 14-17. Kravdal, O. (2004). Child mortality in India: the community-level effect of education. Population Studies, 58(2), 177-192.

Kumar, C., Singh, P. K., \& Rai, R. K. (2012). Under-five mortality in high focus states in India: a district level geospatial analysis. PLoS ONE, 7(5), e37515. http://doi.org/10.1371/journal.pone.0037515.

Ladusingh, L., \& Singh, C. H. (2006). Place, community education, gender and child mortality in northeast India. Population, Space and Place, 12(1), 65-76.

Levine, R. A., \& Rowe, M. L. (2009). Maternal literacy and child health in less-developed countries: evidence, processes, and limitations. Journal of Developmental and Behavioral Pediatrics, 30(4), 340-349.

Mosley, W. H., \& Chen, L. C. (1984). An analytical framework for the study of child survival in developing countries. Population and Development Review, 10, 25-45.

Pradha, J., \& Arokiasamy, P. (2006). High infant and child mortality rates in Orissa: an assessment of major reasons. Population, Space and Place, 12(3), 187-200.

Programme Evaluation Organization. (2011). Evaluation study of National Rural Health Mission in 7 states planning commission. Government of India.

Reddy, H., Pradhan M.R., Ghosh, R., et al. (2012). India's progress towards the Millennium Development Goals 4 and 5 on infant and maternal mortality, WHO South East Asia J Public Health, 1, 279-89.

Registrar General of India (2012). Annual Health Survey 2010-2011, Ministry of Home Affairs, Government of India, New Delhi. http://www.censusindia.gov.in/Common/AHSurvey.html Accessed 2 January 2015.

Registrar General of India and Census commissioner Census of India. (2011). Provisional population totals series 2011. New Delhi: Ministry of Home Affairs, Government of India.

Registrar General of India. (2014). SRS bulletin. Sample Registration System. September, 49(1).

Reichman, N. E., \& Pagnini D. L., (1997). Maternal age and birth outcomes: data from New Jersey. Family Planning Perspectives, 29(6), 268-272 \& 295.

Rodrigues, M., Bonfim, C., Gomes, I., Gurgel, D., \& Medeiros, Z. (2013). Using spatial analysis to identify areas vulnerable to infant mortality. Revista Panamericana de Salud Pública, 34(1), 36-40.

Rodwin, V. G., \& Neuberg, L. G. (2005). Infant mortality and income in 4 world cities: New York, London, Paris, and Tokyo. American Journal of Public Health, 95(1), 86-90.

Saikia, N., Singh, A., Jasilionis, D., \& Ram, F. (2013). Explaining the rural-urban gap in infant mortality in India. Demographic Research, 29, 473-506.

Sastry, N. (1997). Family-level clustering of childhood mortality risk in Northeast Brazil. Population Studies, 51(3), 245-261.

Shi, L., Starfield, B., Kennedy, B., Kawachi, I. (1999). Income inequality, primary care and health indicators. The Journal of Family Practice. 48(4), 275-284

Singh, A., Pathak, P. K., Chauhan, R. K., \& Pan, W. (2011). Infant and child mortality in India in the last two decades: a geospatial analysis. PLoS ONE, 6(11), e26856. http://doi.org/10.1371/journal.pone.0026856.

Singh, P.K., Kumar, C., Rai, R.K., Singh, L. (2013). Factors associated with maternal healthcare services utilization in nine high focus states in India: a multilevel analysis based on 14,385 communities in 292 districts. Plos One. http://doi.org/10.1093/heapol/czt039.

Stockel, J \& Chaudhury, K.M. (1972). Neonatal and post neonatal mortality in rural areas of Bangladesh. Population Studies, 26, 113-120.

Syamala, T. S. (2004). Relationship between socio demographic factors and child survival: evidences from Goa, India. Journal of Human Ecology, 16, 141-145.

Taylor, L. (1975). Poverty, wealth and health or getting the dosage right. British Medical Journal, 4, 207-211.

Vyas, S., \& Kumaranayake, L. (2006). Constructing socio-economic status indices how to use principal component analysis. Health Policy and Planning, 21, 459-468.

Wilkinson, R. G. (1992). Income distribution and life expectancy. British Medical Journal, 304(18), 165-168.

Wilkinson, R. G. (1997). Health inequalities: relative or absolute material standards. British Medical Journal, 314(22), 591-595.

Wilkinson, R. G. (1999). Two pathways, but how much do they diverge? British Medical Journal, 319(22), 956-957. 